\title{
The Role of Information Exposure in Female University Students' Evaluation and Selection of Eco-Friendly Apparel in the South African Emerging Economy
}

\author{
Nadine Sonnenberg', Bertha Jacobs', and Dinele Momberg'
}

\begin{abstract}
Increasing consumption in the South African emerging economy necessitates stringent effort toward developing environmental information campaigns that stimulate preferences for eco-friendly alternatives. This qualitative study explores the role of exposure to information about the environmental impact of the apparel supply chain in female students' evaluation and selection of apparel. Based on the outcome of garment selection exercises and focus group discussions, participants were not swayed by exposure to hang tags, audio-visual or printed information sources to prioritize ecofriendly features in their choice of product, nor were they willing to compromise on attributes such as price for the sake of the environment. Participants' recommendations include standardized ecolabels to facilitate identification of eco-friendly alternatives and message content that is short, precise and factual. Interpersonal communication could represent an influential source of information and merits further investigation into the relevance of normative social influence on proenvironmental apparel behavior in the South African emerging economy.
\end{abstract}

\section{Keywords}

green products, consumer behavior, information processing, information, search, mass media, marketing, environment, sustainability, apparel industry, advertisement

Emerging economies such as South Africa have recently been highlighted in the Living Planet report (World Wide Fund for Nature [WWF], 2012) as having consumption patterns and ecological footprints that increasingly reflect those of high-income industrialized countries. Based on a

\footnotetext{
' Department of Consumer Science, University of Pretoria, Pretoria, South Africa

Corresponding Author:

Nadine Sonnenberg, Department of Consumer Science, University of Pretoria, Pretoria, 0002, South Africa.

Email: nadine.sonnenberg@up.ac.za
} 
classification that incorporates gross domestic product (GDP) per capita at purchasing power parity, emerging economies include countries such as Brazil, Russia, India, China, and South Africa that are distinguished from the least developed countries in terms of economic growth potential (Burgess \& Steenkamp, 2006; Essoussi \& Merunka, 2007). Economic advancement includes several social benefits for these nations, but it also encapsulates environmental consequences such as an increased demand on natural resources, waste management issues, carbon dioxide emissions, and the loss of biodiversity (Mont \& Bleischwitz, 2007; WWF, 2012), which require environmental intervention initiatives similar to those in the developed world (Bodur \& Sarigöllü, 2005; Haron, Paim, \& Yahaya, 2005). Such initiatives may include creating environmental awareness through information provision (Iyer \& Kashyap, 2007; Steg \& Vlek, 2009), stimulating positive attitudes toward environmentally sound alternatives (D’Souza, 2004; Pickett-Baker \& Ozaki, 2008), and creating markets for eco-friendly apparel (Gam, Cao, Farr, \& Kang, 2010; Peterson, Hustvedt, \& Chen, 2012; Ritch \& Schröder, 2012).

In recent years, the South African middle-class consumer segment has grown substantially with increased spending on a broad range of consumer goods including apparel. The demand for clothing is expected to expand by a further $15 \%$ per annum over the 2012-2016 forecast period ("South African Retail and Consumer Products Outlook 2012-2016," 2012). Growth in this sector is linked to environmental implications that accompany each stage of the apparel supply chain (Ritch \& Schröder, 2012). Currently, 90\% of the apparel in South African retail stores is imported ("South African Retail and Consumer Products Outlook 2012-2016," 2012), which in addition to the environmental impact of production has several environmental implications linked to the transportation and distribution of the products (Mont \& Bleischwitz, 2007). Consumer awareness and knowledge of the environmental consequences of the apparel supply chain is thus pertinent to stimulating proenvironmental choices (Chen \& Burns, 2006; Ritch \& Schröder, 2012).

Ideally, a consumer should be able to evaluate the environmental friendliness of a product based on reliable information provided by all role players in the value chain. However, although advances have been made in the supply of eco-friendly apparel, misconceptions based on conflicting and/or misleading information prevail. A typical example includes the assumption that natural fibers such as cotton are more ecofriendly than synthetic fibers (Kadolph \& Langford, 2002). In reality, cotton represents one of the most water- and pesticide-intensive crops in the world (Soth, Grasser, \& Salerno, 1999). Factual information such as the aforementioned is not always readily available (Ritch $\&$ Schröder, 2012). On the other hand, it is not certain whether exposure to such information could endorse ecofriendly apparel choices. In a recent study by Peterson, Hustvedt, and Chen (2012), respondents reacted negatively when exposed to additional information about wool production. Customized approaches whereby information is tailored to the unique characteristics of specific consumer segments seem to be more successful (Steg \& Vlek, 2009). As an example, Lee, Choi, Youn, and Lee (2012) conclude that marketers should distinguish between consumers with low communication involvement who prefer straightforward uncomplicated messages and those with high communication involvement who require detailed information to ascertain the credibility of a proenvironmental claim.

Whether it be uncomplicated or detailed, information is a basic requirement for consumers to make informed decisions as knowledge is a prerequisite to buying behavior and influences every stage of the consumer decision-making process (Laroche, Bergeron, \& Barbaro-Forleo, 2001; Swinker \& Hines, 2006). As pointed out by Ritch and Schröder (2012), consumer demand for eco-friendly apparel depends on information and knowledge about environmental issues, as it will contribute to apparel consumers' confidence in their own proenvironmental choices. In turn, the challenge faced by manufacturers and retailers is to offer consumers affordable and fashionable eco-friendly apparel that complies with proenvironmental principles (Ritch \& Schröder, 2012). Eco-friendly apparel refers to garments that have been created with consideration of the environmental impact of the production process and, when possible, have had harmful processes, chemicals, 
and materials replaced with less harmful substitutes (Brosdahl \& Carpenter, 2010; Joergens, 2006). Environmental consequences linked to the transportation, distribution, consumption, and eventual disposal of the product are also relevant (Mont \& Bleischwitz, 2007).

Although some research has investigated environmental concern and proenvironmental behavior in emerging economies (Bodur \& Sarigöllü, 2005; Chatterjee, 2008), it is not known to what extent exposure to information regarding the environmental impact of the apparel supply chain and/or unsound apparel manufacturing practices (e.g., polluting water with harmful chemicals and producing large amounts of waste water) contribute to consumers' decision to purchase eco-friendly apparel. This contextual gap is specifically relevant in the growing South African apparel industry. Theoretical insights gained from more developed countries do not reflect the complex South African consumer population and thus may be inadequate to inform local promotional campaigns. In the local context, such campaigns are often targeted at younger citizens, since "Generation Y" (i.e., individuals born between 1980 and 1994; Weiler, 2004) constitutes more than half of the South African population (Cant, Brink, \& Brijball, 2006). Students currently enrolled at tertiary institutions belong to this generation (Weiler, 2004). In terms of gender, female students tend to be more receptive to environmentally related information and to engage in proenvironmental behavior (Iyer \& Kashyap, 2007). The objectives of this study were thus focused on exploring and describing the role of exposure to information about environmental issues related to the apparel supply chain from (a) marketing sources (i.e., product labels/ hangtags); (b) media sources (i.e., film clips and magazine articles); and (c) interpersonal sources (i.e., peers/ family) on female university students' evaluation and selection of eco-friendly apparel in the South African context.

\section{Theoretical Background}

\section{Eco-Friendly Apparel Behavior and the Relevance of Information Exposure}

In demonstrating eco-friendly apparel behavior, a consumer would choose apparel items based on attributes that benefit, or cause less harm to, the environment than alternatives (Haron et al., 2005). Ideally, consumers would consider all aspects related to the energy and materials used for the production, packaging, transportation, and distribution of a product as well as its subsequent consumption and eventual disposal, which encompass a so-called "cradle-to-grave" or life cycle analysis (LCA) approach (Mont \& Bleischwitz, 2007; Wagner, 2003). At this stage, the practical implementation of LCA in the local context would seem somewhat optimistic, considering the fairly recent introduction of eco-friendly apparel in the South African retail sector in addition to consumers' limited product experience and the lack of relevant information. That being said, even beyond the South African borders, more experienced consumers in First World countries find it difficult to apply LCA in their assessment of products, as it is complex, time consuming, and often impractical to perform in the retail setting (Wagner, 2003).

Consumers have limitations on their capacity for processing information (Ha-Brookshire, 2012) and are often faced with time and knowledge constraints that result in their use of various cues/heuristics in their decision making (Norum, 2005; Ritch \& Schröder, 2012), especially when the decision problem is complex and unfamiliar (Ha-Brookshire, 2012). One study, for example, found that subjects disregarded approximately half of the available information before making a decision (Solomon \& Rabolt, 2004). However, Wagner (2003) found that consumers, in their willingness to demonstrate proenvironmental behavior, would consider country of origin and opt for a locally produced product rather than an imported alternative based on the assumption that the local product would have less environmental implications. As concluded by Wagner (2003), the resulting evaluation and selection may not live up to scientifically based LCA but is preferable to no proenvironmental effort. This example also illustrates that even limited information such as country of origin can 
serve as a cue to facilitate decisions with potential proenvironmental consequences. Another aspect that should be considered, however, is the source/type of channel through which the information is communicated.

\section{Information Sources}

During the apparel decision-making process, information is obtained from a number of different sources (Swinker \& Hines, 2006), which are utilized differently and to varying degrees of success (Schaefer, Parker, \& Hermans, 2009). Literature distinguishes the main categories of information sources as marketing (which is market dominated), media (which can be market dominated or neutral), objective sources, and personal/interpersonal sources (Solomon \& Rabolt, 2004; Sproles \& Burns, 1994).

Marketing and media sources where the message content is controlled by marketers or retailers (Sproles \& Burns, 1994) includes television, radio, and magazine advertisements as well as product labels and hangtags. Media sources such as television and radio programs as well as magazines and newspaper articles are considered neutral sources because the content is not controlled by marketers (Solomon \& Rabolt, 2004). The role of marketing and media (market dominated or neutral) in increasing consumers' environmental awareness is open to some debate. A study by Joergens (2006) attributed study participants' poor levels of environmental awareness to little or no media coverage. Yet, Essoussi and Merunka (2007) argue that globalization in addition to communication through international media has altered consumers' awareness of pertinent issues in emerging economies. In terms of environmental issues, Haron, Paim, and Yahaya (2005) and Mainieri, Barnett, Valdero, Unipan, and Oskamp (1997) found that respondents' main sources of information were newspapers, television, and radio. However, with regard to fashion and apparel, South African female consumers rated newspaper advertisements and radio talk shows as the least important sources of information, whereas television programs, magazine articles, and magazine advertisements were considered more influential, especially among younger females (Van Staden \& Van Aardt, 2011). Overall, retail store information/advertising was rated as the most influential source of fashion information (Van Staden \& Van Aardt, 2011) and could represent a powerful means to communicate information about eco-friendly apparel.

Product labeling and information found in store are seen as important marketing tools because perceptions about products are formed to some extent by exposure to advertising and/or information on product labels (D’Souza, Taghian, \& Lamb, 2006; Hyllegard, Yan, Paff Ogle, \& Lee, 2012). Product labeling and hangtags usually convey information about the product such as the price, country of origin, brand name, and other characteristics such as fiber content (Hyllegard et al., 2012; Solomon \& Rabolt, 2004). These attributes fulfill an important role in consumers' evaluation and selection of conventional and eco-friendly apparel (Ritch \& Schröder, 2012). Price is often the main criterion for choice in apparel decision making (Norum, 2005; Sproles \& Burns, 1994). Moreover, price and affordability are issues frequently highlighted in consumers' acceptance of eco-friendly alternatives (Gam et al., 2010; Hustvedt \& Bernard, 2010; Ritch \& Schröder, 2012). In addition to price, fabric is considered a prominent estimator of overall quality in apparel products and encompasses many different aspects such as fiber content, type of fabric construction, and tactile characteristics (Fiore \& Damhorst, 1992). In particular, fiber content relates valuable information about the environmental attributes of apparel items, (e.g., organic fibers; Gam et al., 2010; Peterson et al., 2012). Similarly, consumers may derive certain assumptions regarding the environmental impact of a product's supply chain based on its country of origin (Ha-Brookshire, 2012; Wagner, 2003) and form certain perceptions regarding its quality (Essoussi \& Merunka, 2007; Ha-Brookshire, 2012).

Besides communicating product features such as price, fiber content, and country of origin, product labeling/hangtags have also become important mediums through which apparel companies build their brand identity and inform consumers about their commitment to the environment (Hyllegard 
et al., 2012). Self-declarations, which are classified as environmental labels that are not validated by external parties (D’Souza et al., 2006; Joergens, 2006), involve proenvironmental communication regarding a specific brand and/or product (Joergens, 2006). As an example, Woolworths, which is a trusted South African retail brand and recipient of the "International Responsible Retailer" award in 2008, 2010, and 2012, has invested substantial effort into providing information on products in the form of hangtags/labeling that specify the origin and eco-friendly features (e.g., organic fiber content) as part of their "Good Business Journey" campaign (Woolworths Holdings Limited [WHL], 2013). Recent empirical evidence substantiates the positive impact of such campaigns on consumers' eco-friendly apparel behavior (Lee, Choi, Youn, \& Lee, 2012).

Objective sources of information, such as eco-labeling, which are endorsed by third-party certification can also assist consumers in identifying eco-friendly apparel and tend to provide more assurance that a product is made according to environmental standards (D'Souza, 2004; Hyllegard et al., 2012; Joergens, 2006). Globally, many eco-labeling schemes exist that enhance consumers' confidence in the veracity of environmental claims (Rahbar \& Wahid, 2011). Locally, the "Proudly South African" logo is one of few examples of third-party certification. Launched in 2001 by various industry stakeholders, this logo certifies that a product is manufactured in South Africa in accordance with environmental criteria (Irwin, 2004). Although support for the campaign has waned over the past few years, the South African government mandated country of origin labeling in 2008 (Palmi, 2008). As an extension of this enforcement, the "Made in South Africa" label can be applied only to merchandise that has been entirely assembled/manufactured in South Africa (Palmi, 2008). Fiber content is another example of government-mandated information that must appear on apparel labeling (Palmi, 2008). These labels can be important communication mediums that facilitate proenvironmental choice behavior (D’Souza, 2004; Hyllegard et al., 2012), although many consumers also freely admit to paying no attention to labels when shopping for apparel (Joergens, 2006).

Personal communication with friends, family, colleagues, and others is another influential source of information to consider (Mourali, Laroche, \& Pons, 2005; Sproles \& Burns, 1994). People obtain information and guidance from others regarding various types of conduct, including eco-friendly apparel behavior (Kim, Lee \& Hur, 2012). Such guidance is often highly esteemed in emerging market cultures, as they tend to exhibit more collectivistic behavior (Burgess \& Steenkamp, 2006; Tang, Chen, \& Luo, 2011). Although marketers do not have much control over the content of interpersonal communication, it is nonetheless a very persuasive source of information (Solomon \& Rabolt, 2004). Friends, neighbors, and family are often seen as more credible sources, as they have nothing to gain from providing information (Mourali et al., 2005; Sproles \& Burns, 1994). Such information can be more effective than print media, personal selling, or radio advertising in convincing consumers to buy products (Mourali et al., 2005).

In summary, the argument put forward is that through exposure to trustworthy, well-directed information, consumers might be able to improve their memory and knowledge about the domain they are examining and be more confident in their judgments (Laroche et al., 2001; Solomon \& Rabolt, 2004). Message content and explicitness (i.e., the detail and accuracy of the communication) are also relevant in consumers' responses to promotional communication (Hyllegard et al., 2012), which largely depend on the type of communication source. Limited empirical evidence in the South African apparel market regarding the aforementioned aspects substantiated further investigation in the local context.

\section{Method}

The research was exploratory and descriptive in nature, which inspired a qualitative research approach. A cross-sectional study was conducted to understand and describe the phenomena of eco-friendly apparel behavior after exposure to information in the specific context of the South 
African emerging market. Results from this type of study cannot be generalized but may form a useful platform for further quantitative studies.

\section{Sample and Sampling}

A nonprobable purposive sampling technique was used to recruit female students aged 19-22 years who were enrolled at the University of Johannesburg. Johannesburg is the largest metropolis in South Africa and offers access to a broad scope of consumer goods. Urban residents also experience higher levels of mass media exposure, education, and political articulation (Chatterjee, 2008). Environmental educators, marketers, public policy makers, and nongovernmental organizations often focus on the youth (Gentina \& Muratore, 2012), as they are future decision makers in a world that is already confronted with imminent environmental decline. Local efforts are crucial since South Africa is a predominantly young nation. Of a total population of 50 million people, 26 million are aged 24 and younger (National Statistics Offices of the BRICS Group, 2013). Generation Y, which includes current student populations, spends approximately 2 billion ZAR ( $\mathrm{ZAR}= \pm \mathrm{US} \$ 10)$ per annum and is described as pragmatic, socially and environmentally aware, and open to new experiences (Cant et al., 2006). From a marketing perspective, young people tend to be more willing to accept new products (Cant et al., 2006; Solomon \& Rabolt, 2004). In their study among a sample of students, Iyer and Kashyap (2007) conclude that proenvironmental messages/campaigns must be targeted at females because they are more environmentally concerned than males. Although some may argue that female students are less involved and therefore less likely to purchase eco-friendly apparel, recent studies substantiate the relevance of female student samples in exploring topics related to eco-friendly apparel because of females' fashion interest and environmental awareness (Brosdahl \& Carpenter, 2010; Gam, 2009). As emerging consumers with the ability to exert a meaningful contribution toward the preservation of natural resources, female students were deemed an appropriate sample for the exploratory purposes of this study; they were contacted through connections in university residences. Participants $(n=29)$ who volunteered were divided into eight focus groups.

\section{Data Collection}

Qualitative data collection methods were used to explore the phenomena from the participants' point of view. Each data collection session included three to five participants and lasted approximately 1 hr. Smaller groups allowed for more in-depth discussion and participation. As a brief overview, participants were first exposed to a specific source of information and then engaged in a garment selection exercise that simulated an apparel-purchasing scenario. This simulation included actual garments with original in-store labeling and price tags intact. This was followed by focus group discussions during which participants' reasons for choosing specific items in the garment selection exercise were explored. Table 1 summarizes the different types of information sources and content that were included in each of the sessions.

The information sources included in this study are in accordance with those identified in the study of Van Staden and Van Aardt (2011) as the most prevalent sources of fashion information among South African female apparel consumers. As indicated in Table 1, two groups (A and E) were not exposed to any additional information except for the conventional in-store labeling on the garments, which conveyed the retail brand and price as well as government-mandated country of origin and fiber content information. Groups $\mathrm{C}$ and $\mathrm{F}$ were exposed to a short film documenting the environmental impact of clothing production in Lesotho (a neighboring country of South Africa). Groups B and $\mathrm{H}$ were requested to read through a printed magazine article, published in British Vogue, about eco-friendly apparel (Woods, 2006). Fashion magazines such as British Vogue were identified as popular specialized sources of fashion information in the South African context (Van Staden \& Van 
Table I. Focus Group Schedule and Information Exposure.

\begin{tabular}{|c|c|c|}
\hline Information Source & Group & Information Content \\
\hline $\begin{array}{l}\text { In-store and government-mandated } \\
\text { labeling on garments }\end{array}$ & $\begin{array}{l}\text { Group A }(n=5) \\
\text { Group E }(n=3)\end{array}$ & $\begin{array}{l}\text { No additional information, except for the usual } \\
\text { in-store labeling and government-mandated } \\
\text { information }\end{array}$ \\
\hline $\begin{array}{l}\text { Audio-visual media (12-min film clip) in } \\
\text { addition to in-store and government- } \\
\text { mandated labeling }\end{array}$ & $\begin{array}{l}\text { Group C }(n=4) \\
\text { Group F }(n=3)\end{array}$ & $\begin{array}{l}\text { The clip documents the harmful environmental } \\
\text { impact of apparel production in Lesotho. It } \\
\text { specifically focuses on toxic waste and dyes } \\
\text { polluting ground water as well as waste } \\
\text { generated through the production process } \\
\text { that ends up in landfills }\end{array}$ \\
\hline $\begin{array}{l}\text { Printed media (magazine article) } \\
\text { published in the British Vogue, } \\
\text { entitled "Moral Fiber" (Woods, 2006) } \\
\text { in addition to in-store and } \\
\text { government-mandated labeling }\end{array}$ & $\begin{array}{l}\text { Group B }(n=4) \\
\text { Group H }(n=4)\end{array}$ & $\begin{array}{l}\text { The article is about ecological and ethical } \\
\text { fashion. It defines ecofashion as clothing that } \\
\text { is environmentally friendly, that is, using } \\
\text { nontoxic dyes and washes during } \\
\text { production, fewer air miles, and less wasteful } \\
\text { packaging. The article further emphasizes } \\
\text { that cotton is the world's most } \\
\text { environmentally destructive crop (e.g., to } \\
\text { make one white t-shirt requires } 150 \mathrm{~g} \text { of } \\
\text { pesticides) and highlights benefits of organic } \\
\text { cotton and locally grown crops. The article } \\
\text { also includes images of celebrities in } \\
\text { eco-friendly clothes/brands. }\end{array}$ \\
\hline $\begin{array}{l}\text { Eco-friendly self-declaration (extra hang } \\
\text { tag on the organic cotton content } \\
\text { garment) in addition to in-store and } \\
\text { government-mandated labeling }\end{array}$ & $\begin{array}{l}\text { Group D }(n=3) \\
\text { Group G }(n=3)\end{array}$ & $\begin{array}{l}\text { During focus group sessions } \mathrm{D} \text { and } \mathrm{E} \text {, an } \\
\text { additional label was attached to the t-shirt } \\
\text { with organic cotton content that read: "I am } \\
\text { eco-friendly." Additional information was } \\
\text { printed on the back of the label that explains } \\
\text { the benefits of organic cotton and that the } \\
\text { t-shirt had less harmful consequences for the } \\
\text { environment due to the manner in which it } \\
\text { was produced. }\end{array}$ \\
\hline Interpersonal communication & All groups $(n=29)$ & $\begin{array}{l}\text { During focus group discussions, participants } \\
\text { were asked about the role of family and } \\
\text { friends, that is, if they would believe } \\
\text { information about eco-friendly apparel if a } \\
\text { friend or family member told them about it; if } \\
\text { they would consider purchasing eco-friendly } \\
\text { apparel if a friend recommended it; and if } \\
\text { their friends and family had talked to them } \\
\text { about the damaging effects of apparel pro- } \\
\text { duction on the environment }\end{array}$ \\
\hline
\end{tabular}

Aardt, 2011). Groups D and G were exposed to product labeling in the form of an additional hangtag on one of the garments that read, "I am eco-friendly." Participants were asked to read through the information presented on the back of the hangtag, which described the eco-friendly features of the product including the relevance of organic cotton content. The role of interpersonal sources was explored during focus group discussions. Participants were asked about the role of peers and family in their consideration of eco-friendly features and their choice of apparel.

After exposure to information, participants were requested to thoroughly inspect and evaluate the garments presented to them and to choose 1 item from the selection. Field notes were kept with 
Table 2. In-Store and Government-Mandated Labeling on Garments.

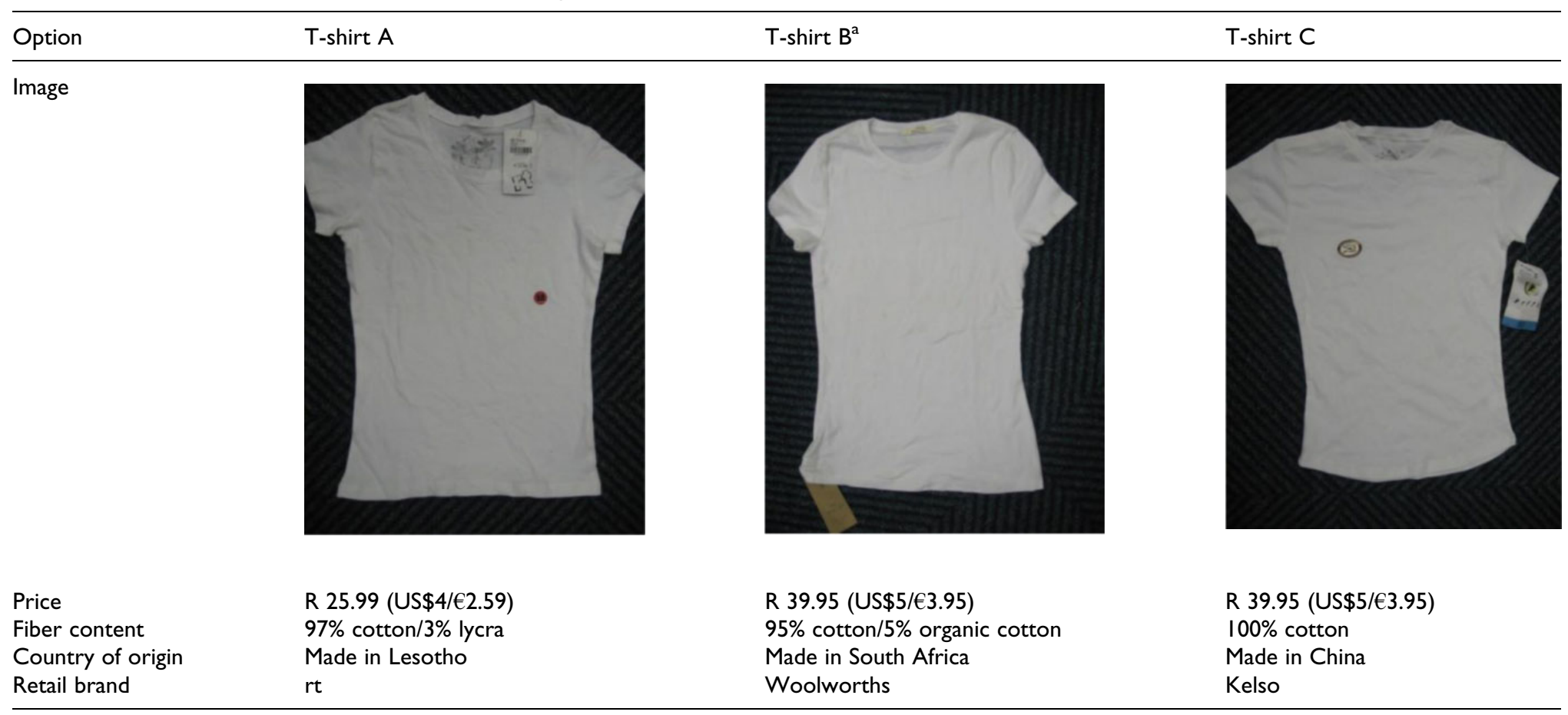

${ }^{\mathrm{a}}$ Based on fiber content and country of origin, t-shirt B is the most eco-friendly option. 
meticulous documentation of participants' inspection and choice of apparel during the garment selection exercise. Based on the evoked set principle (i.e., the set of alternatives actively considered during a consumer's choice process; May-Plumlee \& Little, 2006), three garments in the form of basic white crew neck t-shirts were included in this exercise as illustrated in Table 2. The t-shirts were sourced from the assortment ranges of three prominent South African apparel department stores. Although the t-shirts had slightly different shapes, they were all sized medium; styling attributes were kept as equal as possible in an effort to direct attention to eco-friendly features. Since all of the original in-store labeling and price tags were left intact, participants could assess all the usual product features and information (e.g., brand name, fiber content, and country of origin as summarized in Table 2). Basic white t-shirts were considered appropriate for the garment selection exercise, as they are easy to compare in terms of nonenvironmental criteria such as price and color. As can be gathered from Table 2, t-shirt B was the more eco-friendly option based on its fiber content (i.e., organic cotton blend) and country of origin (i.e., South Africa). The same selection of t-shirts was used for all the focus group sessions. Participants were asked to explain their reasons for choosing a particular garment during the focus group discussions, which were recorded and transcribed verbatim.

\section{Data Analysis}

Data analysis involved managing and organizing the data; reading and writing memos; generating categories, themes, and patterns; coding the data; developing understandings; and drawing conclusions from the data (De Vos, 2004). To begin with, focus group discussions were recorded and transcribed to electronic format. The verbatim transcripts were then sorted into broad categories that were derived from the objectives of the study and relevant literature (Walliman, 2005). Coding is an important part of qualitative research and provides tags or labels used to allocate meaning to the collected data (Walliman, 2005). Through the coding process, the initial data were refined into more specific categories. Similarities or differences within the data were identified, and the main categories were sorted into subcategories. Categories and subcategories were rechecked to reinforce existing analysis or to identify new themes or patterns. The analysis was subsequently submitted to a final peer-review process.

\section{Findings and Discussion}

The findings obtained from the various data collection sessions are presented combined as they apply to the specific items chosen by participants in the garment selection exercise. Participants' reasons for selecting particular options are supported by verbatim quotations from the focus group discussions. Due to word count limitations, only a few quotations are listed. Quotations are labeled according to the specific focus group session from which they originated (listed from A to $\mathrm{H}$ as summarized in Table 1) and the participants (numbered one to five) who took part in the particular focus group session.

\section{Participants' Reasons for Choice and the Role of Information Exposure}

The participants $(n=11)$ who selected the first t-shirt (option A) mentioned price as the deciding factor, regardless of the type of information exposure prior to the garment selection exercise. These participants perceived minimal differentiation between the options presented to them and therefore based their selection on the cost of the item. In referring to price of the t-shirt, one participant summarized her choice as follows: "There's not much of a difference and it is cheap" (Participant G3). Apparently, eco-friendly features were not viewed as differentiating factors for which participants were willing to pay more. Sampling bias and the participant profile for this study may have inflated 
results, as students usually have financial limitations. Yet, as highlighted in a recent consumer report, price sensitivity still guides most South African consumers' decision making, and to date, there is limited support for local businesses' proenvironmental initiatives ("South African Retail and Consumer Products Outlook 2012-2016," 2012).

Only one participant, who had been exposed to the short film documenting the harmful environmental consequences of apparel production in Lesotho, recognized that the t-shirt was made in Lesotho and therefore decided not to choose this particular t-shirt: "I would have liked the material . . . but it's made in Lesotho" (Participant C1). Although the information dissuaded her from choosing the $t$-shirt made in Lesotho, her subsequent choice ( $t$-shirt $C$ ) was not the most eco-friendly alternative in the selection of garments. The short film focused exclusively on apparel production in Lesotho, and therefore no conclusions could be drawn regarding the production of the $t$-shirts that were made in South Africa and China. Yet, in terms of environmental implications linked to the product's distribution and transportation, it could be assumed that the locally produced alternative ( $t$-shirt B) would be more ecofriendly than the China import (t-shirt C). Selecting a product based on such an assumption may fall short of a comprehensive LCA approach, but as pointed out by Wagner (2003), it represents a better choice than one with no environmental consideration. Also, t-shirt B could be assessed as more ecofriendly based on its organic cotton content. Both fiber content and country of origin information is government-mandated labeling, which was left intact on the t-shirts.

The second t-shirt (option B) represented the most eco-friendly option in the selection of garments. Only five participants $(n=5)$ selected this option. Despite the eco-friendly attributes of this t-shirt, participants noted quality as the deciding factor for this item of clothing. Perceived quality is defined by Abraham-Murali and Littrell (1995) as all the properties a consumer deems important. These properties usually include the intrinsic properties of a garment such as durability and fabric. In this case, participants' perception of quality was also influenced by the store's positioning strategy, "Well, it seems like a better quality compared to all . . . if I want to keep it for longer it will be the Woolworths [store/retail brand] one" (Participant D3). Although quality encompasses all the physical and functional performance attributes of a product, two participants also underlined the fabric's tactile quality and stretch in the justification of their decisions, "This one, it feels good and it stretched. It just feels good" (Participant H1).

Only one participant highlighted the garment's eco-friendly status as a choice criterion, "It is slightly better and it is eco-friendly as well" (Participant D2). The t-shirt's eco-friendly status was however simply viewed as an added benefit, as can be deduced from the words "as well." This particular participant formed part of a group that was exposed to additional product labeling. The product labeling could therefore have facilitated the participant's decision-making process and simplified the recognition of environmentally friendly attributes amid various other selection criteria. The other four participants who selected this shirt were not influenced by factual information relating to its environmental qualities, "the fact that it is eco-friendly did not affect my decision" (Participant D4).

The third t-shirt (option C) was the most preferred among participants $(n=13)$. Seven participants $(n=7)$ who selected this option mentioned fabric as the most important consideration in their decision making, "it feels good and it's like not as heavy" (Participant H3) and "I'll also go for this one. The material is stronger" (Participant G2). Three participants also considered functional performance attributes including fit, care, durability, and comfort, "looks as if it can be washed in cold water" (Participant C3) and "looks like it could fit well" (Participant C4). In addition to that mentioned earlier, style (which relates to aesthetic considerations) was mentioned by two participants, "I like the style of the Kelso [retail brand] one" (Participant D1). One participant noted that it was not that much more expensive than the cheapest shirt option, "the price difference is not that much" (Participant G1). In this instance, affordability was not the main barrier to proenvironmental choice because this t-shirt was priced exactly the same as option B (a more eco-friendly alternative). 
In summary, only two instances were recorded whereby exposure to information appeared to have some influence on participants' evaluation and selection of apparel. In both cases, exposure merely aided in positioning eco-friendly attributes as secondary choice criteria, while primary considerations such as price and quality perceptions remained deciding factors. Although participants acknowledged during the focus group discussions that they were concerned about the environment, they did not mention environmental implications linked to features such fiber content and country of origin as reasons for choice. According to May-Plumlee and Little (2006), most products are evaluated based on only five to seven attributes, depending on what the consumer deems most important. Participants' statements confirmed that they were not willing to compromise on certain intrinsic and extrinsic apparel qualities for the sake of the environment. Several studies (Mainieri, Barnett, Valdero, Unipan, and Oskamp, 1997; Pickett-Baker \& Ozaki, 2008) confirm that underlying environmental concern does not necessarily translate into proenvironmental action, and it is therefore pertinent to take into account consumers' expectations and preferences when developing eco-friendly alternatives.

In this study, the choice of apparel and selection criteria also remained consistent regardless of the type of media and information to which participants were exposed. The criteria employed by participants who were not exposed to additional information (Groups A and E) corresponded to that of the other participants (i.e., price, fabric, and perceived quality). Audiovisual and printed media as well as product labeling/hangtags that differentiate eco-friendly features thus seem to have minimal influence in promoting more proenvironmental choices among participants. Yet, as pointed out by Schaefer, Parker, and Hermans (2009), information sources are utilized differently and to varying degrees of success. A combination of information sources (e.g., media exposure and product labeling) utilized in conjunction with each other may be more effective in promoting proenvironmental options. As pointed out by Rahbar and Wahid (2011), the objective of proenvironmental marketing is to influence consumers' behavior by encouraging them to buy proenvironmental products; in order for this to happen, all of the relevant dimensions of a product need to be marketed through various marketing channels.

Interpersonal information was the final source of information that was explored in the focus group discussions, as it may represent an influential medium of promoting preference toward eco-friendly apparel, especially in emerging market cultures. Participants in all of the focus group discussions agreed that they valued the opinions of their friends and family and would be even more inclined to follow their advice if they were knowledgeable about eco-friendly apparel. As summarized by a participant in Group H, "So, I guess if the friend was well informed and you could ask why or what ... so if they knew that kind of detail then they could probably persuade me to buy it" (Participant H2). A friend's ability to persuade them would however still remain subject to the aesthetic appeal of the garment, "Not like ooh, I bought an organic thing and it's not looking so good on you" (Participant H4). Behavior often occurs in a social context and the influence of social norms and word-of-mouth information on proenvironmental behavior has been extensively documented in the current literature (Mourali et al., 2005; Pickett-Baker \& Ozaki, 2008). As a further example, Kim, Lee, and Hur (2012) emphasize the pertinence of social influence in consumers' acceptance of eco-friendly apparel.

\section{Participants' Recommendations Regarding the Use of Media and Product Labeling}

As a by-product of the qualitative research process, and given the aim of the study - namely to explore the role of information exposure-participants were asked how information relating to eco-friendly apparel could be presented and communicated more effectively. In terms of popular media, some participants suggested that information pertaining to eco-friendly apparel should be broadcast by means of advertisements and talk shows on radio and/or television. The message content should explain relevant concepts (e.g., eco-friendly), provide factual information relating to the environmental implications of a product, and be presented in a believable and credible manner. 
These suggestions correspond with conclusions drawn from the studies of Ashill and Yavas (2005) as well as Hyllegard, Yan, Paff Ogle, and Lee (2012), which advise apparel firms to avoid the use of vague terms and images in advertising that deceptively imply eco-friendly endorsement. Although some of the participants were of the opinion that eco-friendly apparel did not enjoy enough exposure in the media, others felt that even if it did, advertisements might not be the most appropriate method, as they may not reach all of the intended audience: "at home when there is an ad you quickly run to do something and then come back to the programme and you don't really see the ad" (Participant D2).

In a similar vein, participants' views regarding the use of magazines and other printed media to promote eco-friendly apparel were also characterized by a degree of cynicism. Unless the headings and topics of discussion were of interest to them, they would not be inclined to read articles published in magazines. Some participants also questioned the credibility of information about environmental issues that is featured in fashion magazines. To them, the concept of fashion and the fashion industry in general is not yet linked to environmental practices, and they hence doubt the ability of fashion magazines to accurately report on such matters. Prior empirical evidence underscores the importance of accuracy in promotional communication when shared understanding about a particular topic is limited (Hyllegard et al., 2012). Misleading claims severely impact consumers' trust and can easily evolve into a consumer backlash against green marketing (Thøgersen, 2006). Participants advised that alternative forms of printed media, such as billboards, in-store posters, or pamphlets, could be explored and that printed messages should be concise, factual, and of practical value, "It must not be a long publication that no one ever reads ... people don't want to sit there and read a five page long, how to deal with" (Participant D3). These suggestions closely relate to the recommendations of Lee et al. (2012) who advise marketers to approach people who have low marketing communication involvement with simple and clear messages as opposed to detailed information.

In terms of product labeling, participants mentioned that they seldom read information on clothing labels or hangtags. This also became apparent during the garment selection exercise when none of the participants read the additional information printed on the back of the eco-friendly t-shirt's hangtag, despite the prior briefing and request to read all of the information provided on the hangtag. Participants recommended that positioning and visibility of hangtags are of primary importance in drawing attention to the fact that garments have eco-friendly features, "I never even look at the label... So, like it should be like a sticker... on the front" (Participant C3). Standardized symbols/logos that signify third-party certification were also suggested, "Maybe if they had standardized symbols or something for clothes as well" (Participant G2). Recommendations of Hyllegard et al. (2012) that call for the inclusion of third-party certification and logos that specifically relate to the apparel industry are thus substantiated in the South African context. Retailers are also advised to pay more attention to the in-store information, especially in light of the fact that apparel decision-making frequently occurs in stores (Solomon \& Rabolt, 2004). Overall, more opportunities need to be created for consumers to form conversant opinions regarding ecofriendly alternatives (Pickett-Baker \& Ozaki, 2008).

\section{Conclusion}

The findings of this study contribute to literature regarding the role of different types of information (i.e., media and product labeling) on consumers' eco-friendly apparel behavior. Exposure to audiovisual and printed information as well as product hangtags did not convince participants to prioritize eco-friendly product features. It is concluded from this study that participants based their apparel selection on attributes such as price and were not swayed to consider the eco-friendly qualities such as organic cotton fiber content. Despite their voiced concern for the environment, they were not willing to forfeit their preferences and usual apparel criteria. Although this may suggest that eco-friendly 
apparel has not yet gained full acceptance in the South African context, it is imperative for manufacturers and other role players in the apparel supply chain to continue efforts toward developing and marketing products that comply with proenvironmental principles. Given that consumers may use multiple channels when searching for information, it is suggested that a variety of information sources should be used concurrently, with greater emphasis on eco-friendly apparel that is comparable to other nonenvironmental options in terms of aesthetics, functionality, performance, and price.

Since knowledge and understanding of the impact of apparel on the environment is still limited, it is suggested that information campaigns are extended with message content that is precise and factual. Concise, visible, and accurate messages that explain the environmental implications of a product's supply chain could ensure that aspects such as country of origin feature more prominently in consumers' evaluation and selection of garments. In conjunction, a more stringent effort toward standardized third-party certification is required. Apparel products are difficult to evaluate, as many different factors influence the environmental impact of a garment (Hustvedt \& Bernard, 2010). Apart from the Proudly South African logo, clearly identifiable third-party certification does not exist in the South African apparel market, and therefore environmentally concerned consumers would have difficulty in sourcing suitable products in stores. Standardized labels that denote sound environmental practices in the apparel supply chain should allow for ease of recognition and evaluation of eco-friendly options, thereby instilling more confidence in consumers' proenvironmental choices. A greater awareness and understanding of government-mandated labeling such as the "Made in South Africa" label should also be cultivated among local consumers. Based on the findings of the focus group discussions, interpersonal communication could also represent an influential source of information and point to the augmented relevance of normative social influence on proenvironmental behavior in emerging economies, as proposed by Tang, Chen, and Luo, (2011). Further investigation is needed in this regard, as this study was exploratory and narrowly focused on female university students' evaluation and selection of eco-friendly apparel in the South African context.

\section{Limitations and Recommendations for Future Research}

Although the findings of this study cannot be generalized, it does provide a useful platform for further quantitative research and the development of quantitative measures to assess the influence of information exposure and participants' rating of environmental attributes in relation to other nonenvironmental criteria. To improve the generalizability of findings, future research may benefit from larger samples with more encompassing demographic profiles. Although most studies conducted in developed countries reflect demographic inconsistencies in relation to consumers' environmental concern and eco-friendly behavior (Kim et al., 2012), certain demographic characteristics may be worthy of further investigation in the South African emerging economy, especially in light of cultural differences and income inequalities, which add complexity toward shaping proenvironmental action. Furthermore, this study focused mainly on the role of information exposure, whereas extant research highlights the significance of various other factors such as values, beliefs, norms, situational determinants, and previous experience that impact consumers' willingness to engage in eco-friendly behavior. Future research may therefore want to establish the relevance of these variables in conjunction with information exposure as it applies to the specific behavior in question. Humans are complex beings, and additional sources of information other than those investigated in this study may be relevant and considered for future empirical investigation. Finally, the crosssectional nature of this study did not allow for an unequivocal clarification of the role of prolonged exposure to information on eco-friendly apparel behavior. Thus, future research could adopt a more longitudinal approach, whereby the effect of information exposure could be assessed after an appropriate incubation period and in terms of a wider scope of apparel products. 


\section{Author's Note}

The role of information exposure in female university students' evaluation and selection of eco-friendly apparel in the South African emerging economy

\section{Declaration of Conflicting Interests}

The author(s) declared no potential conflicts of interest with respect to the research, authorship, and/or publication of this article.

\section{Funding}

The author(s) received no financial support for the research, authorship, and/or publication of this article.

\section{References}

Abraham-Murali, L., \& Littrell, M. A. (1995). Consumers' perceptions of apparel quality over time: An exploratory study. Clothing and Textiles Research Journal, 13, 49-158.

Ashill, N. J., \& Yavas, U. (2005). Importance of information sources and media evaluations: A cross-national study. Cross-Cultural Management, 12, 51-62.

Bodur, M., \& Sarigöllü, E. (2005). Environmental sensitivity in a developing country: Consumer classification and implications. Environment and Behavior, 37, 487-510.

Brosdahl, D. J. C., \& Carpenter, J. M. (2010). Consumer knowledge of the environmental impacts of textile and apparel production, concern for the environment, and environmentally friendly consumption behavior. Journal of Textile and Apparel Technology and Management, 6, 1-9.

Burgess, S. M., \& Steenkamp, J. E. M. (2006). Marketing renaissance: How research in emerging markets advances marketing science and practice. International Journal of Research in Marketing, 23, 337-356.

Cant, M. C., Brink, A., \& Brijball, S. (2006). Consumer behaviour. Cape Town, South Africa: Juta.

Chatterjee, D. P. (2008). Oriental disadvantage versus occidental exuberance: Appraising environmental concern in India-A case study in a local context. International Sociology, 23, 5-33.

Chen, H. L., \& Burns, L. D. (2006). Environmental analysis of textile products. Clothing and Textile Research Journal, 24, 248-261.

D'Souza, C. (2004). Green advertising effects on attitude and choice of advertising themes. Corporate Communications: An International Journal, 9, 179-188.

D’Souza, C., Taghian, M., \& Lamb, P. (2006). An empirical study on the influence of environmental labels on consumers. Corporate Communications: An International Journal, 11, 162-173.

De Vos, A. S. (2005). Qualitative data analysis and interpretation In A. S. De Vos, H. Strydom, C. B. Fouché, \& C. S. L. Delport (Eds.), Research at grass roots. For the social sciences and human service professions (3rd ed., pp. 333-349). Pretoria, South Africa: Van Schaik.

Essoussi, L. H., \& Merunka, D. (2007). Consumers' product evaluations in emerging markets: Does country of design, country of manufacture, or brand image matter? International Marketing Review, 24, 409-426.

Fiore, A. M., \& Damhorst, M. L. (1992). Intrinsic cues as predictors of perceived quality of apparel. Journal of Consumer Satisfaction, Dissatisfaction and Complaining Behaviour, 5, 168-178.

Gam, H. J. (2009). Are fashion-conscious consumers more likely to adopt eco-friendly clothing? Journal of Fashion Marketing and Management, 15, 178-193.

Gam, H. J., Cao, H., Farr, C., \& Kang, M. (2010). Quest for the eco-apparel market: A study of mothers' willingness to purchase organic cotton clothing for their children. International Journal of Consumer Studies, $34,648-656$.

Gentina, E., \& Muratore, I. (2012). Environmentalism at home: The process of ecological resocialization by teenagers. Journal of Consumer Behaviour, 11, 162-169.

Ha-Brookshire, J. E. (2012). Country of parts, country of manufacturing, and country of origin: Consumer purchase preferences and the impact of perceived prices. Clothing and Textiles Research Journal, 30, $19-34$. 
Haron, S. A., Paim, L., \& Yahaya, N. (2005). Towards sustainable consumption: An examination of environmental knowledge among Malaysians. International Journal of Consumer Studies, 29, 426-436.

Hustvedt, G., \& Bernard, J. C. (2010). Effects of social responsibility labelling and brand on willingness to pay for apparel. International Journal of Consumer Studies, 34, 619-626.

Hyllegard, K. H., Yan, R., Paff Ogle, J., \& Lee, K. (2012). Socially responsible labeling: The impact of hang tags on consumers' attitudes and patronage intentions toward an apparel brand. Clothing and Textiles Research Journal, 30, 51-66.

Irwin, R. (2004, May 31). South Africa makes it local. brandchannel. Retrieved from http://www.brandchannel. com/features_effect.asp?pf_id=212

Iyer, E. S., \& Kashyap, R. K. (2007). Consumer recycling: Role of incentives, information, and social class. Journal of Consumer Behaviour, 6, 32-47.

Joergens, C. (2006). Ethical fashion: Myth or future trend? Journal of Fashion Marketing and Management, 10, $360-371$.

Kadolph, S. J., \& Langford, A. L. (2002). Textiles (9thed.). Upper Saddle River, NJ: Prentice Hall.

Kim, H., Lee, E., \& Hur, W. (2012). The normative social influence on eco-friendly consumer behavior: The moderating effect of environmental marketing claims. Clothing and Textiles Research Journal, $30,4-18$.

Laroche, M., Bergeron, J., \& Barbaro-Forleo, G. (2001). Targeting consumers who are willing to pay more for environmentally friendly products. Journal of Consumer Marketing, 18, 503-520.

Lee, N., Choi, Y. J., Youn, C., \& Lee, Y. (2012). Does green fashion retailing make consumers more ecofriendly? The influence of green fashion products and campaigns on green consciousness and behavior. Clothing and Textiles Research Journal, 30, 67-82.

Mainieri, T., Barnett, E. G., Valdero, T. R., Unipan, J. B., \& Oskamp, S. (1997). Green buying: The influence of environmental concern on consumer behaviour. The Journal of Social Psychology, 13, 189-204.

May-Plumlee, T., \& Little, T. J. (2006). Proactive product development integrating consumer requirements. International Journal of Clothing Science and Technology, 18, 53-66.

Mont, O., \& Bleischwitz, R. (2007). Sustainable consumption and resource management in the light of life cycle thinking. European Environment, 17, 59-76.

Mourali, M., Laroche, M., \& Pons, F. (2005). Antecedents of consumer relative preference for interpersonal information sources in pre-purchase search. Journal of Consumer Behaviour, 4, 307-318.

National Statistics Offices of the BRICS Group. (2013). BRICS joint statistical publication (4th ed.). Retrieved from: http://www.statssa.gov.za/news_archive/Docs/FINAL_BRICS\%20PUBLICATION_PRINT_23\%20 MARCH\%202013_Reworked.pdf

Norum, P. S. (2005). A comparison of apparel garment prices by national, retail, and private labels. Clothing and Textiles Research Journal, 21, 142-148.

Palmi, R. (2008, May 13). "Country of origin" label regulations enforced. Retrieved from http://www.fibre2fashion.com/industry-article/11/1061/country-of-origin2.asp

Peterson, H. H., Hustvedt, G. M., \& Chen, Y. (2012). Consumer preferences for sustainable wool products in the United States. Clothing and Textiles Research Journal, 30, 35-50.

Pickett-Baker, J., \& Ozaki, R. (2008). Pro-environmental products: Marketing influence on consumer purchase decision. Journal of Consumer Marketing, 25, 281-293.

Rahbar, E., \& Wahid, N. A. (2011).Investigation of green marketing tools' effect on consumers' purchase behaviour. Business Strategy Series, 12, 73-83.

Ritch, E. L., \& Schröder, M. J. (2012). Accessing and affording sustainability: The experience of fashion consumption within young families. International Journal of Consumer Studies, 36, 203-210.

Schaefer, A. D., Parker, R. S., \& Hermans, C. M. (2009). Information source usage in teen apparel purchases: China, Japan and the United States. Journal of Fashion Marketing and Management, 13, 541-552.

Solomon, M. R., \& Rabolt, N. J. (2004). Consumer Behavior in Fashion. Upper Saddle River, NJ: PrenticeHall. 
Soth, J., Grasser, C., \& Salerno, R. (1999). The impact of cotton on fresh water resources and ecosystems: A preliminary synthesis. Retrieved from http://awsassets.panda.org/downloads/impact_long.pdf

South African Retail and Consumer Products Outlook 2012-2016. (2012). Pricewaterhouse coopers (PwC) \& economist intelligence unit. Retrieved from http://www.pwc.co.za/en/publications/retail-and-consumeroutlook.jhtml

Sproles, G. B., \& Burns, L. D. (1994). Changing appearances. New York, NY: Fairchild.

Steg, L., \& Vlek, C. (2009). Encouraging pro-environmental behavior: An integrative review and research agenda. Journal of Environmental Psychology, 29, 309-317.

Swinker, M. E., \& Hines, J. D. (2006). Understanding consumers' perception of clothing quality: A multidimensional approach. International Journal of Consumer Studies, 30, 218-223.

Tang, Z., Chen, X., \& Luo, J. (2011). Determining socio-psychological drivers for rural household recycling behavior in developing countries: A case study from Wugan, Hunan, China. Environment and Behavior, $43,848-877$.

Thøgersen, J. (2006). Media attention and the market for "green" consumer products. Business Strategy and the Environment, 15, 145-156.

Van Staden, J., \& Van Aardt, A. M. (2011). Information seeking by female apparel consumers in South Africa during the fashion decision-making process. International Journal of Consumer Studies, 35, 35-49.

Wagner, S. A. (2003). Understanding green consumer behaviour: A qualitative cognitive approach. London, England: Routledge.

Walliman, N. (2005). Your research project. (2nd ed.). London, England: Sage.

Weiler, A. (2004). Information-seeking behavior in generation Y students: Motivation, critical thinking and learning theory. Journal of Academic Librarianship, 31, 46-53.

Woods, V. (2006, October). Moral fiber. Vogue, 172, 319-123.

Woolworths Holdings Limited (WHL). (2013). 2013 good business journey report. Retrieved from http://www. woolworthsholdings.co.za/investor/annual_reports/ar2013/GBJ_Web_2013.pdf

World Wide Fund for Nature (WWF). (2012). Living planet report 2012: Biodiversity, biocapacity and better choices. Retrieved from http://awsassets.panda.org/downloads/1_lpr_2012_online_full_size_single_pages_ final_120516.pdf

\section{Author Biographies}

Nadine Sonnenberg is a lecturer in the Department of Consumer Science, University of Pretoria, South Africa. Her research interests include environmentally responsible consumer behavior in the clothing and interior merchandise categories with particular emphasis on the complexities of emerging market contexts.

Bertha Jacobs is a lecturer in the Department of Consumer Science, University of Pretoria, South Africa. Her research interests include fashion retailing, clothing merchandising, social psychology of clothing, and the professional development of students for industry.

Dinele Momberg is currently enrolled as a PhD student at the Department of Consumer Science, University of Pretoria, South Africa. She has extensive experience in the South African clothing industry, and her research interest is focused on environmentally responsible consumer behavior in the South African clothing sector. 